\title{
Synergistic effect of angiotensin II type 1 receptor genotype and poor glycaemic control on risk of nephropathy in IDDM
}

\author{
A. Doria, T. Onuma, J.H. Warram, A.S. Krolewski \\ Section on Epidemiology and Genetics, Research Division, Joslin Diabetes Center \\ Department of Medicine, Harvard Medical School, Boston, Massachusetts, USA
}

Summary We investigated the contribution of polymorphisms in the angiotensin II type 1 receptor gene ( $A G T R 1)$ to renal complications in an inception cohort of 152 insulin-dependent diabetic (IDDM) patients examined 15-21 years after diabetes onset. This nested case-control study included 79 normoalbuminuric control subjects and 73 cases with evidence of nephropathy ranging from microalbuminuria to overt proteinuria. Subjects were genotyped for two $A G T R 1$ polymorphisms $\left(\mathrm{T}^{573} \rightarrow \mathrm{C}\right.$ and $\left.\mathrm{A}^{1166} \rightarrow \mathrm{C}\right)$, and an adjacent $\mathrm{CA}$ repeat microsatellite. Allele $\mathrm{C}^{1166}$ and the $140 \mathrm{bp}$ allele of the microsatellite were more frequent among nephropathy cases than normoalbuminuric control subjects $(0.322$ vs 0.247 , and 0.618 vs 0.521 , respectively), but these differences were not statistically significant. Although not significant by themselves, the $A G T R 1$ polymorphisms contributed significantly to the risk of diabetic nephropathy when accompanied by poor glycaemic control. Among patients with frequent severe hypergly- caemia during the first decade of diabetes, the relative risk of nephropathy among allele $\mathrm{C}^{1166}$ carriers was 12.1 (95\% CI: 3.7-39.8), whereas it was only 1.4 (95\% CI: 0.6-3.5) among allele $\mathrm{A}^{1166}$ homozygotes. The difference between relative risks was highly significant $\left(\chi^{2}=8.25, p=0.004\right.$ with $\left.1 d f\right)$. A similar pattern of higher risk of microalbuminuria, specifically among those carriers of allele $\mathrm{C}^{1166}$ who had poor glycaemic control was also found in an independent study of a cross-sectional sample of 551 IDDM individuals, although the effect was smaller in magnitude. We conclude that DNA sequence differences in the AGTRI gene may modify the noxious effects of hyperglycaemia on the kidney. Allele $\mathrm{C}^{1166}$ carriers might especially benefit from nephropathy prevention programmes. [Diabetologia (1997) 40: 1293-1299]

Keywords Insulin-dependent diabetes mellitus, diabetic nephropathy, angiotensin II receptor, DNA polymorphisms, genetics.
Less than half of the patients with insulin-dependent diabetes mellitus (IDDM) develop diabetic nephropathy, which represents the major predictor of morbidity and premature mortality among these individuals $[1,2]$. Why this complication develops in only a

Received: 4 March 1997 and in revised form: 18 June 1997

Corresponding author: A. S. Krolewski, M. D. Ph.D., Section on Epidemiology and Genetics, Joslin Diabetes Center, One Joslin Place, Boston, MA 02215, USA

Abbreviations: IDDM, insulin-dependent diabetes mellitus; ACE, angiotensin converting enzyme; AER, albumin excretion rate; ACR, albumin creatinine ratio; DGGE, denaturing gradient gel electrophoresis subset of IDDM patients is not known. Poor glycaemic control has been recognized as a major determinant of renal complications in IDDM [3, 4], but other factors, unrelated to hyperglycaemia, also appear to be operating. The recent finding of familial clustering of diabetic nephropathy suggests that renal complications in IDDM are the result of an interaction between the diabetic milieu and nephropathy predisposing genetic factors [5-7].

The search for the identity of the genes underlying predisposition to nephropathy is a very active area of research [8]. Since several studies have shown that familial predisposition to essential hypertension is associated with increased risk of diabetic nephropathy [9$11]$, most of the candidate genes have been selected 
from among loci involved in the regulation of blood pressure. The genes coding for the renin-angiotensin system have attracted special attention because angiotensin II, beside increasing systemic blood pressure, has several intrarenal effects that may act as powerful co-factors in the development of glomerular alterations. These effects include both alterations of renal haemodynamics, such as an increase in intraglomerular pressure, and direct stimulation of mesangial cell proliferation and matrix production $[12,13]$. Thus, genetic variability in angiotensin II generation and/or action may contribute to variability in susceptibility to diabetic nephropathy. Further support for this hypothesis has been provided by clinical studies showing that inhibition of angiotensin II generation by angiotensin converting enzyme (ACE) inhibitors retards the progression of diabetic nephropathy [14].

The genes of the renin-angiotensin system include renin $(R E N)$, angiotensinogen $(A G T)$, angiotensinconverting enzyme $(A C E)$, and at least two types of angiotensin II receptors ( $A G T R 1$, the subtype through which most of angiotensin II actions are exerted, and $A G T R 2$, whose function is uncertain [15]. While only one report has been published on the $R E N$ gene, showing a lack of association with diabetic nephropathy [16], several groups have investigated the relationships between $A G T$ and $A C E$ genes and renal complications with inconsistent results $[8,17-$ 24]. Regardless of the controversies, however, it is clear that neither of these loci has an effect on the risk of nephropathy large enough to account for the observed familial clustering of renal complications in IDDM.

We have investigated the association between nephropathy in IDDM and three polymorphisms in the $A G T R 1$ gene, one of which $\left(\mathrm{A}^{1166} \rightarrow \mathrm{C}\right)$ has been previously found to be weakly associated with essential hypertension in the general population [25]. Since hyperglycaemia is the best described and, probably, the most important predictor of diabetic nephropathy, we have also studied whether these polymorphisms may influence susceptibility to renal complications in IDDM by magnifying the effect of poor glycaemic control on the risk of nephropathy.

\section{Subjects, materials and methods}

Study population. Individuals selected for this study were the participants in a nested case-control study of determinants of late diabetic complications that was conducted between 1986 and 1988 in a well-defined cohort of patients who had had IDDM for 15 to 21 years [11]. DNA was still available in 1994-1995 for 152 (94\%) of the 162 participants; 79 of these were normoalbuminuric (referred to as normoalbuminuria group), and 73 had a variable degree of diabetic nephropathy (nephropathy group). The selection and evaluation of these patients has been described in detail previously [11]. The evaluation of renal status included measurements of fasting serum
Table 1. Clinical characteristics of study patients according to renal status when examined 15 to 21 years after diagnosis of juvenile-onset IDDM

\begin{tabular}{lll}
\hline & $\begin{array}{l}\text { Normoal- } \\
\text { buminuria }\end{array}$ & $\begin{array}{l}\text { Nephro- } \\
\text { pathy }\end{array}$ \\
\hline$n$ (male/female) & $79(38 / 41)$ & $73(35 / 38)$ \\
Age at IDDM diagnosis (years) & $12 \pm 5$ & $11 \pm 4$ \\
Age at examination (years) & $30 \pm 5$ & $29 \pm 4$ \\
Albumin excretion rate $(\mu \mathrm{g} / \mathrm{min})$ & $8 \pm 7$ & $1558 \pm 2561$ \\
Microalbuminuria $(n)$ & - & 32 \\
Overt proteinuria $(n)$ & - & 41 \\
Impaired renal function $(n)$ & - & 16 \\
Systolic blood pressure $(\mathrm{mm} \mathrm{Hg})$ & $118 \pm 14$ & $134 \pm 21^{\mathrm{a}}$ \\
Diastolic blood pressure $(\mathrm{mm} \mathrm{Hg})$ & $78 \pm 11$ & $87 \pm 14^{\mathrm{a}}$ \\
Antihypertensive drugs $(\%)$ & 1 & 37 \\
Parental hypertension $(\%)$ & 49 & 59 \\
Index of hyperglycaemia $(\%)$ & $39 \pm 19$ & $54 \pm 19^{\mathrm{a}}$ \\
HbA $(\%)$ & $10.9 \pm 1.9$ & $12.0 \pm 2.0^{\mathrm{a}}$ \\
\hline Data are means & &
\end{tabular}

Data are means \pm SD.

${ }^{\mathrm{a}} p<0.001$

creatinine, and albumin excretion rate (AER) during a 3-h timed urine collection performed in the morning. Normoalbuminuria was defined as an AER under $30 \mu \mathrm{g} / \mathrm{min}$. Overt proteinuria was defined as an AER $250 \mu \mathrm{g} / \mathrm{min}$ or more including patients on haemodialysis or with renal transplant. Microalbuminuria was defined as the range between normoalbuminuria and overt proteinuria. Patients were considered hypertensive if they were on antihypertensive drugs, or the average of two supine measurements (standard sphygmomanometer) of systolic or diastolic blood pressure was equal to or greater than 140 or $90 \mathrm{mmHg}$, respectively. Parental history of hypertension was ascertained by questionnaires mailed to the parents of patients and was considered positive if at least one parent had hypertension diagnosed and treated before age 60 years. An index of the frequency of hyperglycaemia during the first 12 years of IDDM was computed for each patient from clinical records as previously described [10]. The index is the percentage of the total number of blood glucose values (in $\mathrm{mg} / \mathrm{dl}$ ), recorded during visits to the Joslin Clinic before 1981 that exceeded the following criteria: 180 fasting; 240 less than $1.5 \mathrm{~h}$ after eating; 2201.5 to $2.4 \mathrm{~h}$ after eating; 2002.5 to $3.4 \mathrm{~h}$ after eating; and $1803.5 \mathrm{~h}$ or more after eating. Table 1 summarizes the clinical characteristics of these individuals.

Additional study subjects. To confirm some of the findings in the main study population, the influence of glycaemic control on the relationship between the AGTR1 $\mathrm{A}^{1166} \rightarrow \mathrm{C}$ polymorphism and the risk of microalbuminuria was investigated in a cross-sectional sample of 551 IDDM patients from a study of the natural history of microalbuminuria that is being conducted at the Joslin Clinic. The selection and evaluation of patients for this study has been described in detail previously [4]. In brief, all patients enrolled in this study $(n=1613)$ are Caucasian residents of Massachusetts and had IDDM onset before age 41 years. They came to the Joslin Clinic soon after the diagnosis of IDDM (on average 3 years) and have remained under the care of the clinic ever since. The evaluation of renal status was based on measurements of the albumin to creatinine ratio (ACR) in multiple random urine samples collected at the time of clinic visits during 1991-1993 [4]. Normoalbuminuria was defined as an ACR less than $17 \mu \mathrm{g} / \mathrm{mg}$ for men and less than $25 \mu \mathrm{g} / \mathrm{mg}$ for women (1.9 and $2.8 \mathrm{mg} / \mathrm{mmol}$, respectively). Overt proteinuria was defined as an ACR greater than $250 \mathrm{mg}$ / $\mathrm{mg}$ for men or greater than 355 for women $(28$ and $40 \mathrm{mg}$ / 
mmol, respectively) or a reagent strip reading $2+$ or more. $\mathrm{Mi}$ croalbuminuria was defined as an ACR in the range between normoalbuminuria and overt proteinuria. Classification of a patient's renal status was based on a consensus of two out of three determinations. Of the 1613 patients screened, 1117 were normoalbuminuric, 295 had microalbuminuria, and 201 overt proteinuria [4]. We selected 410 normoalbuminuric and 141 microalbuminuric individuals for the present study. While the index of hyperglycaemia during the first 12 years of diabetes was not available for this additional study group, haemoglobin $A_{1}$ measurements during the 2 years preceding the determination of nephropathy (1990-1991) were available, and the geometric mean of these measurements was used as an index of long term glycaemic control, as previously described [4]. Since the values of recent haemoglobin $A_{1}$ measurements no longer correlate well with long term glycaemic control once overt proteinuria is established, patients with persistent proteinuria were excluded from the study [4].

$D N A$ analysis. The main study population was genotyped for three polymorphisms in the $A G T R 1$ gene and adjacent regions: $\mathrm{T}^{573} \rightarrow \mathrm{C}-$ a conservative substitution in the $A G T R 1$ coding region [24], $\mathrm{A}^{1166} \rightarrow \mathrm{C}$-located in the AGTR1 3' untranslated region $[25,26]$, and a CA repeat microsatellite placed about $15 \mathrm{~kb} 3^{\prime}$ of the $A G T R 1$ gene [27]. The 551 additional study subjects were genotyped for the $A^{1166} \rightarrow C$ polymorphism only.

$\mathrm{T}^{573} \rightarrow \mathrm{C}$ genotypes were determined by PCR amplification of genomic DNA followed by denaturing gradient gel electrophoresis (DGGE). A 236 bp fragment including AGTR1 CDNA position 573 was amplified by PCR using a forward primer (5'-CCTGGCTATTGTTCACCC-3') and a reverse primer (5'-CGCCGCAACCCAGTATATTTTTGG-3'). The latter carried a 6 bp 'GC-clamp' at the 5' end (in bold face) to facilitate DGGE analysis. PCR was performed on $0.5 \mu \mathrm{g}$ of DNA in $50 \mu \mathrm{l}$ containing TRIS $\mathrm{HCl} 10 \mathrm{mmol} / \mathrm{l} \mathrm{pH} 8.3, \mathrm{KCl} 50 \mathrm{mmol} /$ $1, \mathrm{MgCl}_{2} 1.5 \mathrm{mmol} / \mathrm{l}$, gelatin $0.001 \%$, each dNTP $0.2 \mathrm{mmol} / \mathrm{l}$, each primer $0.25 \mathrm{mmol} / 1$, Taq polymerase (Amplitaq, Perkin Elmer, Norwalk, Conn., USA) $25 \mathrm{U} / \mathrm{ml}$, for 30 cycles $(60 \mathrm{~s}$ at $95^{\circ}, 60 \mathrm{~s}$ at $52^{\circ}, 60 \mathrm{~s}$ at $72^{\circ}$ ) in a Perkin Elmer Thermal Cycler 480. DGGE was performed according to a previously described protocol [28] in an $8 \%$ polyacrylamide gel with a linear gradient of denaturants from 10 to $50 \%(100 \%=7 \mathrm{~mol} / \mathrm{l}$ urea in $40 \%$ formamide) in $1 \times$ Tris-Acetate-EDTA (TAE) buffer at a constant temperature of $60^{\circ}$ at $10 \mathrm{~V} / \mathrm{cm}$ for $4.5 \mathrm{~h}$. Under these conditions allele $\mathrm{T}^{573}$ is recognized as a band stopping at $31 \%$ of denaturant concentration, allele $\mathrm{C}^{573}$ as a band stopping at $32 \%$.

Genotyping of $\mathrm{A}^{1166} \rightarrow \mathrm{C}$ was carried out by PCR followed by $D d e I$ digestions and agarose electrophoresis as previously described [26]. The CA microsatellite was genotyped by $[\gamma-$ ${ }^{32}$ P]ATP labelled PCR followed by denaturing polyacrylamide gel electrophoresis as described by Davies et al. [27]. A total of eight alleles were detected in our population. Genotype distributions determined with these methods did not significantly depart from Hardy-Weinberg equilibrium in any of the study groups.

Statistical analysis. Allele frequencies were computed from genotype frequencies. The distribution of genotypes and alleles were compared between study groups by chi-square tests [29]. Haplotype frequencies were estimated by gene counting as previously described [30]. As a descriptive measure of association between genotypes and outcomes, odds ratios were calculated along with $95 \%$ confidence intervals [29]. Odds ratios were compared by the Breslow-Day test. Logistic regression analysis was used to assess the independent contributions of risk factors to the development of diabetic nephropathy.

\section{Results}

AGTR1 polymorphisms and diabetic nephropathy. Only small differences in allele and genotype distributions were observed between cases and control subjects for all three polymorphisms (Table 2). Allele $\mathrm{C}^{1166}$, which had previously been found to be weakly associated with essential hypertension [25], was not significantly more frequent in the nephropathy group than among normoalbuminuric individuals $(0.322$ vs $0.247, \chi^{2}=2.1, p=0.15$ with $1 d f$ ) (Table 2). Similarly, the nephropathy risk among $\mathrm{C}^{1166}$ allele carriers (heterozygotes and $C^{1166}$ homozygotes) was not significantly higher than that of $\mathrm{A}^{1166}$ homozygotes (Table 2). Similar results were obtained when IDDM individuals with microalbuminuria and overt proteinuria or end-stage renal failure were considered separately (data not shown). The major allele of the AGTR1 microsatellite (\# 4, $140 \mathrm{bp}$, indicated as $\mathrm{A}_{1}$ in Table 2) showed a weak, non-significant association with nephropathy $(0.618$ in cases vs 0.521 in control subjects, $\chi^{2}=2.8, p=0.24$ with $2 d f$ ). In order to consider these polymorphisms simultaneously, we used gene counting methods to estimate the distribution of haplotypes defined by the two polymorphisms in cases and control subjects. Carriers of the haplotype defined by allele $\mathrm{C}^{1166}$ and microsatellite allele \#4 had a 2.8-fold risk of diabetic nephropathy relative to carriers of other genotypes (95\% CI: 1.4-5.8). While this comparison has a $p$-value of 0.004 , the weight given to this finding must be tempered by the number of comparisons made; for example, there were eight possible pairings of alleles of the microsatellite with the apparent risk allele $C^{1166}$. Therefore, from Bonferroni's inequality, one may argue that the $p$-value is closer to 0.032 . No significant association with arterial hypertension could be found for any of the AGTRI polymorphisms within each renal group (data not shown).

Interaction between AGTR1 polymorphisms and poor glycaemic control. We also asked whether AGTRI polymorphisms, despite a weak association with renal complications in the total group, might contribute importantly to susceptibility to diabetic nephropathy in the presence of poor glycaemic control. Individuals whose index of severe hyperglycaemia was above the median for the overall population had a 3.5-fold risk of diabetic nephropathy relative to individuals whose index of hyperglycaemia was below the median (95\% CI: 1.7-3.5) (Table 3). The magnitude of this risk, however, depended strongly on the $\mathrm{A}^{1166} \rightarrow \mathrm{C}$ genotype. Among carriers of the allele $\mathrm{C}^{1166}$ the nephropathy risk associated with an index of hyperglycaemia above the median was 12.1 (3.7-39.8), while it was only $1.4(0.6-3.5)$ among non-carriers (i.e. allele $\mathrm{A}^{1166}$ homozygotes) (Table 3 ). The difference between the odds ratios was highly 
Table 2. Comparison of genotype and allele frequencies for $\mathrm{T}^{573} \rightarrow \mathrm{C}, \mathrm{A}^{1166} \rightarrow \mathrm{C}$, and $A G T R 1$ microsatellite in IDDM subjects with and without nephropathy

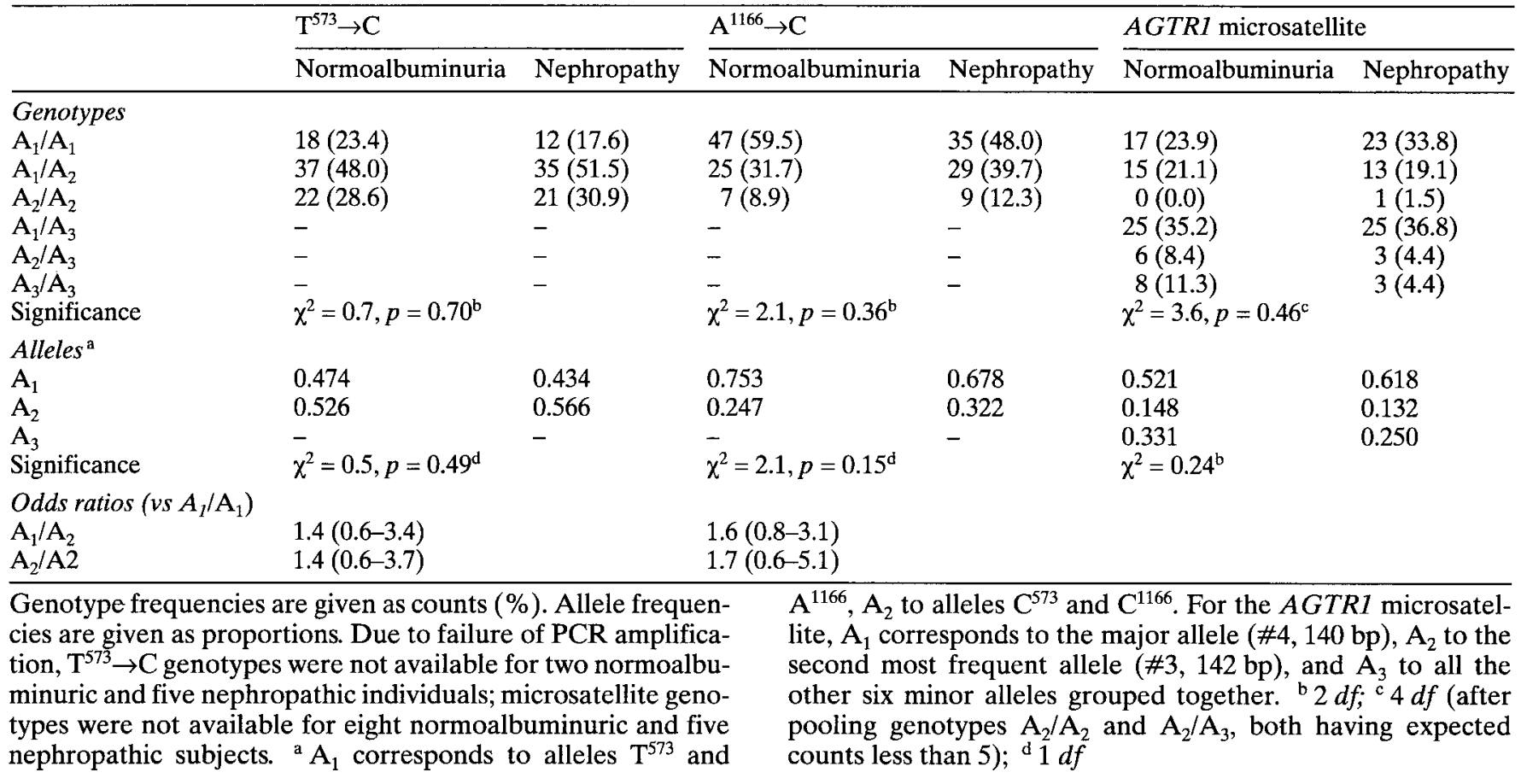

Table 3. Index of hyperglycaemia during first 12 years of diabetes and risk of nephropathy among carriers and non-carriers of $A G T R 1$ allele $\mathrm{C}^{1166}$

\begin{tabular}{|c|c|c|c|c|c|c|}
\hline & \multicolumn{2}{|l|}{ All } & \multicolumn{2}{|l|}{$\mathrm{C}^{1166}$ Non-carriers } & \multicolumn{2}{|l|}{$\mathrm{C}^{1166}$ carriers } \\
\hline & Normoalbuminuria & Nephropathy & Normoalbuminuria & Nephropathy & Normoalbuminuria & Nephropathy \\
\hline $\begin{array}{l}\text { Index of hyperglycaemia } \\
\text { Below median } \\
\text { Above median }\end{array}$ & $\begin{array}{l}47 \\
26\end{array}$ & $\begin{array}{l}23 \\
44\end{array}$ & $\begin{array}{l}25 \\
19\end{array}$ & $\begin{array}{l}16 \\
17\end{array}$ & $\begin{array}{r}22 \\
7\end{array}$ & $\begin{array}{r}7 \\
27\end{array}$ \\
\hline $\begin{array}{l}\text { Odds ratio } \\
95 \% \text { Confidence interval }\end{array}$ & $\begin{array}{l}3.5 \\
(1.7-6.9)\end{array}$ & & $\begin{array}{l}1.4 \\
(0.6-3.5)\end{array}$ & & $\begin{array}{l}12.1^{\mathrm{b}} \\
(3.7-39.8)\end{array}$ & \\
\hline
\end{tabular}

${ }^{a}$ Omitted are 12 individuals (six cases and six control subjects) for whom the index of hyperglycaemia was not available.

${ }^{\mathrm{b}} \chi^{2}=8.25, p=0.004$ with $1 d f$ for the difference between odds ratios among $\mathrm{C}^{1166}$ carriers and non-carriers (Breslow-Day test)

significant $\left(\chi^{2}=8.25, p=0.004\right.$ with $\left.1 d f\right)$. A similar risk difference was observed when carrier status for haplotype $\mathrm{C}^{1166}$-microsatellite allele \#4 rather than the whole allele $\mathrm{C}^{1166}$ was used to subdivide individuals (data not shown). Since the AGTR1 gene is involved in the control of blood pressure and increased blood pressure in parents has been shown to be a determinant of nephropathy in IDDM $[9,10,11]$, we examined whether this effect of allele $C^{1166}$ may be due to an increased prevalence of parental hypertension among carriers. No association, however, was found between allele $C^{1166}$ and presence of hypertension in parents within each renal group. Further, the effect of allele $\mathrm{C}^{1166}$ on the risk of nephropathy associated with poor glycaemic control was present and similar among IDDM individuals with and without a parental history of hypertension, indicating that the allele $\mathrm{C}^{1166}$ and parental history of hypertension contribute independently to the risk of nephropathy (data not shown).

To confirm the significant interaction between poor glycaemic control and $A^{1166} \rightarrow C$ genotype, we investigated an additional sample of 551 IDDM patients from a cross-sectional study conducted at the Joslin Clinic [4]. The clinical characteristics of these subjects are illustrated in Table 4 . In this population, allele $C^{1166}$ frequency was 0.266 in the normoalbuminuria and 0.282 in the microalbuminuria group $\left(\chi^{2}=0.25, p=0.62\right.$ with $\left.1 d f\right)$. No significant association with hypertension was detected within each renal group (data not shown). Since we do not have data to calculate an index of hyperglycaemia during the first 12 years of diabetes, the mean glycated haemoglobin level in the years 1990-1991 was used as an index of long term glycaemic control, as described in Methods [4]. The risk of microalbuminuria rose 
Table 4. Clinical characteristics of patients from the natural history of microalbuminuria study according to renal status

\begin{tabular}{lll}
\hline & $\begin{array}{l}\text { Normoal- } \\
\text { buminuria }\end{array}$ & $\begin{array}{l}\text { Microal- } \\
\text { buminuria }\end{array}$ \\
\hline$n$ (male/female) & $410(209 / 201)$ & $141(71 / 70)$ \\
Age at IDDM diagnosis (years) & $17 \pm 7$ & $15 \pm 7$ \\
Age at examination (years) & $29 \pm 7$ & $31 \pm 7$ \\
Albumin/creatinine ratio $(\mu \mathrm{g} / \mathrm{mg})$ & $12 \pm 4$ & $90 \pm 74$ \\
Systolic blood pressure (mm Hg) & $125 \pm 15$ & $133 \pm 16^{\mathrm{a}}$ \\
Diastolic blood pressure (mm Hg) & $70 \pm 11$ & $76 \pm 9^{\mathrm{a}}$ \\
Antihypertensive drugs (\%) & 4 & $24^{\mathrm{a}}$ \\
HbA $_{1}(\%)$ & $10.3 \pm 1.8$ & $10.9 \pm 2.0^{\mathrm{a}}$ \\
\hline
\end{tabular}

Data are means $\pm S D$.

${ }^{\mathrm{a}} p<0.001$

$\mathrm{HbA}_{1}$ represents the geometric mean of $\mathrm{HbA}_{1}$ values during 1988 and 1990-1991

with increasing glycated haemoglobin values regardless of $A G T R 1$ genotype (Fig. 1) [4]. Above a glycated haemoglobin of $11 \%$, however, the risk of microalbuminuria increased more steeply in carriers than in non-carriers of allele $\mathrm{C}^{1166}$ (Fig.1). Among carriers, poor glycaemic control (glycated haemoglobin value of $12 \%$ ) carried a 2.6 -fold risk of microalbuminuria (C.I.:1.02-6.4); whereas, among non-carriers, the relative risk was only 1.6 (C.I.:0.7-3.8). Thus, this additional data set seems to show the same modifying effect of $A G T R 1$ allele $\mathrm{C}^{1166}$ on the relationship between poor glycaemic control and the risk of nephropathy, but the magnitude of the interaction in a cross-sectional study design is less strong and is not statistically significant with this sample size.

\section{Discussion}

In this study, we investigated the $A G T R 1$ gene as a candidate locus for susceptibility to diabetic nephropathy. In a cohort of 152 IDDM individuals examined between 15 and 21 years after diabetes onset, we could not find any significant association between diabetic nephropathy and $A G T R 1$ allele $\mathrm{C}^{1166}$. Although allele $C^{1166}$ by itself did not contribute significantly to renal complications, we observed a powerful, significant interaction between this allele and poor glycaemic control in determining the risk of diabetic nephropathy. Among carriers of allele $\mathrm{C}^{1166}$, the relative risk of renal complications associated with frequent severe hyperglycaemia in the first decade of diabetes was almost ten times that observed among $\mathrm{A}^{1166}$ homozygotes (12.1 vs 1.4$)$. A similar pattern of interaction between allele $\mathrm{C}^{1166}$ and poor glycaemic control was observed in a cross-sectional sample of 551 IDDM individuals currently attending the Joslin Clinic. Hyperglycaemia was associated with higher risk of nephropathy among $\mathrm{C}^{1166}$ carriers than non-carriers, although the estimate of this magnifying

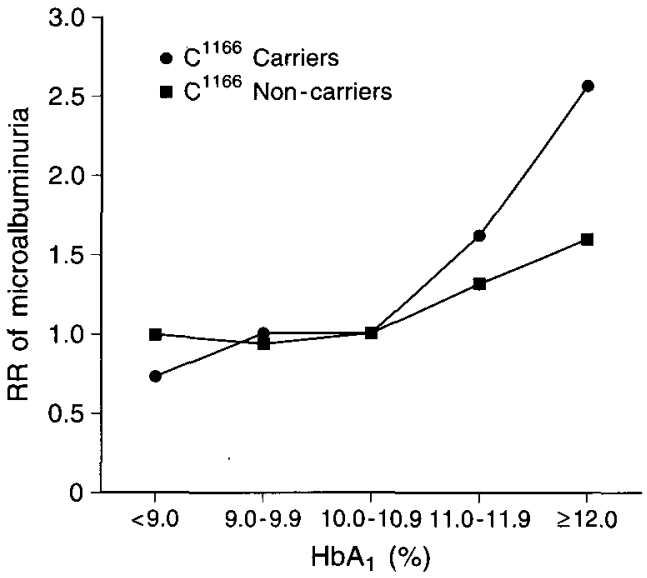

Fig. 1. Relation between mean haemoglobin $A_{1}$ values and risk of microalbuminuria among carriers (- $\left.\boldsymbol{\Delta}_{-}\right)$and non-carriers (-- --) of $A G T R 1$ allele $\mathrm{C}^{1166}$ in the additional study population. Odds ratios were calculated taking the allele $C^{1166}$ non-carriers with haemoglobin $A_{1}$ lower than $9 \%$ as the reference group. The $95 \%$ confidence intervals for odds ratios were respectively $0.3-1.9,0.4-2.5,0.4-2.7,0.7-4.0$, and $1.0-6.4$ for the five haemoglobin $A_{1}$ classes among carriers of allele $C^{1166}$, and $0.4-2.3,0.4-2.4,0.5-3.3$, and $0.7-3.8$ for the four upper classes among non-carriers

effect in carriers of this allele was much smaller in this study design and not detectable with this sample size.

Our findings suggest that IDDM individuals carrying the AGTR1 allele $C^{1166}$ are particularly susceptible to the damage caused by hyperglycaemia and would especially benefit from good glycaemic control. While our findings are striking, association studies are subject to error [31], and this interaction between poor glycaemic control and the AGTRI allele $\mathrm{C}^{1166}$ must be confirmed in other populations and corroborated by cellular studies, before allele $\mathrm{C}^{1166}$ carriers are preferentially selected for intensified treatment programmes. There are several reasons, however, for confidence in the validity of the present findings. First, our study population was a sample from a well-defined inception cohort of IDDM patients who were ascertained regardless of their attendance at the Joslin Clinic after diabetes diagnosis. All individuals were Caucasian and resided in Massachusetts. Thus, biases in patient selection or the presence of population stratification, are unlikely. A second consideration is that the $p$-value for the difference between odds ratios was small $(p=0.004)$, making it also unlikely that these findings were a type I error. Finally, findings consistent with this interpretation were obtained in a second, independent sample of IDDM patients. While the interaction between allele $\mathrm{C}^{1166}$ and the effect of hyperglycaemia on the risk of nephropathy was not statistically significant in the second sample, this was likely due to the less powerful study design, a cross-sectional sample from which patients with advanced nephropathy were excluded 
due to the unavailability of a suitable long term measure of glycaemic control [4].

The AGTR1 gene spans $47 \mathrm{~kb}$ on chromosome $3 q 22$ and consists of five exons, four of which are untranslated and alternatively spliced [32]. The open reading frame is entirely contained in exon 5 , and codes for a $41 \mathrm{kDa}$ seven-transmembrane domain protein which binds angiotensin II and mediates most of its actions on the kidney and vessels [15]. The $\mathrm{A}^{1166} \rightarrow \mathrm{C}$ transversion is located at the 5' end of the 3' untranslated region on the same exon as the open reading frame $[25,26]$ and is not known to have any biological function. Therefore, we hypothesize that the observed synergism with glycaemic control might be due to linkage disequilibrium between allele $C^{1166}$ and other sequence differences, as yet unidentified but possibly located in regulatory regions. These polymorphisms may increase AGTR1 expression, enhance angiotensin II action, and ultimately increase kidney susceptibility to the effect of hyperglycaemia through abnormalities of systemic or renal haemodynamics, or by altering the function of renal cells [33, 34]. Since both angiotensin II and excess glucose activate protein kinase $\mathrm{C}$, the interaction between poor glycaemic control and the renin angiotensin system might take place along this signal transduction pathway $[35,36]$.

In conclusion, our data provide preliminary evidence that genetic variability at the $A G T R 1$ locus potentiates the effect of poor glycaemic control on the risk of diabetic nephropathy. If confirmed, these results may provide a basis for identifying IDDM individuals who would benefit most from good glycaemic control. Studying the cellular pathways linking AGTR1 variability to the effects of hyperglycaemia may also lead to new insights in the cellular mechanisms by which diabetes causes glomerular alterations. Knowledge of these mechanisms might suggest additional strategies for preventing diabetic nephropathy and its burden of morbidity and mortality among patients with IDDM.

Acknowledgements. This work was supported by grant DK41526 from the National Institute of Health. Dr. Tomio Onuma was supported by a grant from the Ministry of Education of Japan.

\section{References}

1. Krolewski AS, Warram JH (1994) Epidemiology of late complications of diabetes. In: Kahn CR, Weir G (eds). Joslin's diabetes mellitus, 13th edn. Lea \& Febiger, Philadelphia pp 605-619

2. Andersen AR, Christiansen JS, Andersen JK, Kreiner S, Deckert T (1983) Diabetic nephropathy in Type I (insulindependent) diabetes: an epidemiologic study. Diabetologia 25: 496-501

3. DCCT Research Group (1993) The effect of intensive treatment of diabetes on the development and progression of long term complications in insulin-dependent diabetes mellitus. N Engl J Med 329: 977-986

4. Krolewski AS, Laffel LMB, Krolewski M, Quinn M, Warram JH (1995) Glycated haemoglobin and risk of microalbuminuria in patients with insulin-dependent diabetes mellitus. N Engl J Med 332: 1252-1255

5. Seaquist ER, Goetz FC, Rich S, Barbosa J (1989) Familial clustering of diabetic kidney disease: evidence for genetic susceptibility to diabetic nephropathy. N Engl J Med 320: 1161-1165

6. Borch-Johnsen K, Nørgaard K, Hommel E et al. (1992) Is diabetic nephropathy an inherited complication? Kidney Int. 41: 719-722

7. Quinn M, Angelico MC, Warram JH, Krolewski AS (1996) Familial factors determine the development of diabetic nephropathy in patients with IDDM. Diabetologia 39: 940-945

8. Doria A, Warram JH, Krolewski AS (1995) Genetic susceptibility to nephropathy in IDDM: from epidemiology to molecular genetics. Diab Metab Rev 11: 287-314

9. Viberti GC, Keen H, Wiseman MJ (1987) Raised arterial pressure in parents of proteinuric insulin dependent diabetics. BMJ 295: 515-517

10. Krolewski AS, Canessa M, Warram JH et al. (1988) Predisposition to hypertension and susceptibility to renal disease in insulin-dependent diabetes mellitus. $\mathrm{N}$ Engl J Med 318: 140-145

11. Barzilay J, Warram JH, Bak M, Laffel LMB, Canessa M, Krolewski AS (1992) Predisposition to hypertension: risk factor for nephropathy and hypertension in IDDM. Kidney Int 41: 723-730

12. Ballerman BJ, Zeidel ML, Gunning ME, Brenner BM (1991) Vasoactive peptides and the kidney. In: Brenner BM, Rector FC (eds) The kidney, 4th ed. Saunders, Philadelphia, pp 510-583

13. Egido J (1996) Vasoactive hormones and renal sclerosis. Kidney Int 49: 578-597

14. Lewis EJ, Hunsicker LG, Bain RP, Rohde RD (1993) The effect of angiotensin-converting enzyme inhibition on diabetic nephropathy. N Engl J Med 329: 1456-1462

15. Clauser E, Curnow, KM, Davies E, Conchon S, Teutsch B, Vianello B, Corvol P (1996) Angiotensin II receptors: protein and gene structures, expression and potential pathological involvements. Eur J Endocrinol 134: 403-411

16. Angelico MC, Laffel LMB, Krolewski AS (1993) Application of denaturing gradient gel electrophoresis to detect DNA polymorphisms in the renin gene in IDDM patients with and without nephropathy. In: Belfiore F, Bergman RN, Molinatti GM (eds) Current topics in diabetic research, vol 12. Karger, Basel, pp. 227-230

17. Tarnow L, Cambien F, Rossing P et al. (1996) Angiotensinogen gene polymorphism in IDDM patients with diabetic nephropathy. Diabetes 45: 367-369

18. Doria A, Onuma T, Gearin G, Freire MB, Warram JH, Krolewski AS (1996) Angiotensinogen polymorphism M235T, hypertension, and nephropathy in insulin-dependent diabetes. Hypertension 27: 1134-1139

19. Fogarty DG, Harron JC, Hughes AE, Nevin NC, Doherty CC, Maxwell AP (1996) A molecular variant of angiotensinogen is associated with diabetic nephropathy in IDDM. Diabetes 45: 1204-1208

20. Marre M, Bernadet P, Gallois Y et al. (1994) Relationship between angiotensin I converting enzyme gene polymorphism, plasma levels and diabetic retinal and renal complications. Diabetes 43: 384-388

21. Doria A, Warram JH, Krolewski AS (1994) Genetic predisposition to diabetic nephropathy: evidence for a role of the 
angiotensin I-converting enzyme gene. Diabetes 43: 690695

22. Schmidt S, Schone N, Ritz E, and the Diabetic Nephropathy Study Group (1995) Association of ACE gene polymorphism and diabetic nephropathy? Kidney Int 47: 1176-1181

23. Tarnow L, Cambien F, Rossing P et al. (1995) Lack of relationship between an insertion/deletion polymorphism in the angiotensin I-converting enzyme gene and diabetic nephropathy and proliferative retinopathy in IDDM patients. Diabetes 44: 489-494

24. Barnas U, Schmidt A, Illievich A et al. (1997) Evaluation of risk factors for the development of nephropathy in patients with IDDM: insertion/deletion angiotensin converting enzyme polymorphism, hypertension, and metabolic control. Diabetologia 40: 327-331

25. Bonnardeaux A, Davies E, Jeunemaitre X et al. (1994) Angiotensin II type I receptor gene polymorphism in human essential hypertension. Hypertension 24: 63-69

26. Doria A, Ji L, Warram JH, Krolewski AS (1994) DdeI polymorphism in the AGTR1 gene. Hum Mol Genet 3: 1444

27. Davies E, Bonnardeaux A, Lathrop GM, Clauser E, Soubrier F (1994) Angiotensin II (type 1) receptor locus: CA repeat polymorphism and genetic mapping. Hum Mol Genet 3: 838

28. Parker S, Angelico MC, Laffel, L, Krolewski AS (1993) Application of denaturing gradient gel electrophoresis to detect DNA sequence differences encoding apolipoprotein $\mathrm{E}$ isoforms. Genomics 16: 245-247
29. Rothman KJ (1986) Modern epidemiology. Little, Brown \& Company, Boston, MA, pp 85-114

30. Doria A, Warram JH, Rich SS, Krolewski AS (1994) Angiotensin I-converting enzyme (ACE): estimation of DNA haplotypes in unrelated individuals using denaturing gradient gel blots. Hum Genet 94: 117-123

31. Cox NJ, Bell GI (1989) Disease associations: chance, artifacts, or susceptibility genes? Diabetes 39: 947-950

32. Curnow KM, Pascoe L, Davies E, White PC, Corvol P, Clauser C (1995) Alternatively spliced human type 1 angiotensin II receptor mRNA are translated at different efficiencies and encode two receptor isoforms. Mol Endocrinol 9: $1250-1262$

33. Mogensen CE, Christiansen CK (1984) Predicting diabetic nephropathy in insulin-dependent patients. $\mathrm{N}$ Engl J Med 311: 89-93

34. Kagami S, Border WA, Miller DE, Noble NA (1994) Angiotensin II stimulates extracellular matrix protein synthesis through induction of transforming growth factor-b expression in rat glomerular mesangial cells. J Clin Invest 93: 2431-2437

35. Griendling KK, Rittenhouse SE, Brock TA, Ekstein LS, Gimbrone MA, Alexander RW (1986) Sustained diacylglycerol formation from inositol phospholipids in angiotensin II-stimulated vascular smooth muscle cells. J Biol Chem 261: 5901-5906

36. Derubertis FR, Craven PA (1994) Activation of protein kinase $\mathrm{C}$ in glomerular cells in diabetes. Mechanisms and potential links to the pathogenesis of diabetic glomerulopathy. Diabetes $43: 1-8$ 